\title{
UMA ANÁLISE SOBRE O EMPREGO SETORIAL BRASILEIRO ${ }^{1}$
}

\author{
Rodrigo Silva Barreto ${ }^{2}$ \\ Silvia Harumi Toyoshima ${ }^{3}$ \\ Guilherme Marciano Timm ${ }^{4}$ \\ Tárik L. F. Pereira Navarro 5
}

\begin{abstract}
Resumo: O objetivo deste artigo foi avaliar o impacto das transformações da economia brasileira na estrutura do emprego setorial, no período 1988-2006, buscando identificar as causas primárias que explicam a dispersão setorial do emprego, tendo como marco a abertura comercial brasileira e, principalmente, o Plano Real. A metodologia utilizada consistiu no cálculo de um índice de dispersão setorial do emprego e num teste de correlação entre este índice e um índice normalizado do número de vagas de trabalho. $\mathrm{O}$ resultado obtido foi que, antes da implementação do Plano Real, os movimentos de demanda setorial foram os principais responsáveis pelas alterações setoriais do emprego, enquanto após sua implementação, em 1994, verificaram-se movimentos setoriais puros, que foram atribuídos à reestruturação tecnológica, organizacional e produtiva. A partir de 2004, os resultados indicam que os efeitos da reestruturação econômica se reduziram e as alterações setoriais do emprego passaram a ocorrer novamente, devido aos movimentos de demanda setorial.
\end{abstract}

Palavras-chave: dispersão setorial do emprego, reestruturação produtiva, tecnológica e organizacional, alterações na demanda.

Recebido em: 04/09/09; Aceito em: 19/02/10.

2 Graduado pela Universidade Federal de Viçosa. E-mail: rodbarreto@uol.com.br.

3 Professora Associada do Departamento de Economia da Universidade Federal de Viçosa. E-mail: htsilvia@ufv.br.

4 Estudante de Graduação da Universidade Federal de Viçosa. E-mail: gmtimm@gmail.com.

5 Estudante de Graduação da Universidade Federal de Viçosa. E-mail: tariknavarro@gmail.com 


\section{Introdução}

O objetivo deste artigo foi avaliar o impacto das transformações recentes da economia brasileira na estrutura do emprego setorial, buscando identificar as causas primárias que levaram à dispersão setorial do emprego - tendo como marco a abertura comercial brasileira e, principalmente, o Plano Real.

A maior exposição do país à concorrência externa e à entrada de capitais estrangeiros, fenômenos intrínsecos ao processo de globalização ${ }^{6}$, tem transformado a estrutura produtiva do país e, consequentemente, gerado impactos diretos no denominado mundo do trabalho. A busca de competitividade da economia brasileira no âmbito internacional, por meio de difusão dos atuais paradigmas tecnológico, organizacional e institucional disseminados nos países mais desenvolvidos, elevou substancialmente a produtividade e alterou o perfil da demanda do emprego em todos os segmentos produtivos (MATTOSO, 1995).

Explicitamente, os problemas de ajuste estrutural ocorrem, principalmente, em virtude do processo de realocação dos recursos entre os diversos segmentos produtivos. Tal processo leva a alterações e desequilíbrios estruturais, devido às taxas de mudanças técnicas e organizacionais desiguais entre esses segmentos. As taxas de crescimento dos vários ramos produtivos da economia também variam, levando alguns a aumentar sua participação no PIB, enquanto outros a reduzem, ou seja, as inovações não são apenas difundidas irregularmente no tempo, mas geram, também, influências diferenciadas nos vários segmentos produtivos da economia, além de criar outros "novos" (SCHUMPETER, 1961). Tal processo faz com que a demanda de trabalho sofra choques que atingem, de forma diferente, os setores.

As mudanças setoriais do emprego têm despertado atenção entre os economistas, nas últimas décadas, uma vez que estas podem influenciar a taxa de desemprego agregada. Lucas e Prescott (1974), por exemplo, concluíram que há uma taxa de desemprego natural constante na 
Rodrigo Silva Barreto, Silvia Harumi Toyoshima, Guilherme Marciano Timm \&

Tárik L. F. Pereira Navarro

economia, provocada pelos deslocamentos do emprego entre setores, para acomodar-se à demanda. Empiricamente, Lillien (1982) demonstrou que há, de fato, correlação positiva entre a dispersão setorial e a taxa de desemprego; todavia, essa taxa natural de desemprego não é constante, mas variável ao longo do tempo. Alguns estudiosos, entretanto, observam que não são apenas os choques realocativos do emprego entre setores que afetam o nível de emprego, mas também os choques de demanda agregada. Abraham e Katz (1986) mostraram que a dispersão do emprego setorial pode apresentar correlação endógena com os movimentos da demanda agregada.

No Brasil, Reis e Gonzaga (2000), ao testarem os impactos da dispersão setorial do emprego na taxa de desemprego, utilizaram estimações com modelos VAR (vetores autorregressivos), com o intuito de selecionar e identificar um modelo estrutural baseado no Índice de Dispersão do Emprego. Esses autores constataram que os choques de demanda agregada, no período 1983-1997, afetaram em apenas 10\% o índice de dispersão setorial. Os choques aleatórios, por sua vez, influenciaram, de maneira expressiva (40\%), a taxa de desemprego na década de 80 e início da de 90. No entanto, a partir de 1995, outros fatores não explicados pelo modelo, relacionados com o aumento de desemprego estrutural, passaram a influenciar, significativamente, a taxa de desemprego, como o processo de estabilização da economia, a redução da flexibilidade do salário real e as mudanças estruturais provocadas pelas transformações nos paradigmas produtivo e tecnológico.

As teorias dos trabalhos, acima citadas, sobre o emprego setorial serviram, assim, de suporte teórico para o cálculo da dispersão setorial do emprego e, consequentemente, para a identificação das principais causas deste. Este trabalho procurou distinguir os dois tipos de choques predominantes que causam a dispersão setorial do emprego: os de demanda - provocados por alterações na demanda agregada; e os aleatórios - provocados por outros fatores, que foram atribuídos à reestruturação produtiva, organizacional e tecnológica, partindo da metodologia utilizada por Abraham e Katz (1986). O período analisado compreendeu os anos 1988 
a 2006, a fim de comparar as alterações ocorridas no processo produtivo antes e depois da abertura comercial e da implementação do Plano Real. A abertura comercial, a partir de 1990, foi um fator desencadeador das mudanças mencionadas, mas estas foram acentuadas pelo Plano Real. Portanto, o estudo procurou enfatizar a fase anterior e posterior à implantação do Plano Real, que, por incentivar a adoção de novas tecnologias e processos por meio da maior entrada de produtos estrangeiros, tendeu a ser um fator gerador de choques aleatórios. Por último, fez-se uma análise das mudanças ocorridas, na virada do século, na economia brasileira sobre o emprego setorial desencadeado a partir da maxi-desvalorização cambial em janeiro de 1999.

Partiu-se do pressuposto que, nos anos oitenta, as alterações na demanda setorial do emprego deveram-se, predominantemente, a choques de demanda agregada, devido às variações da demanda agregada, com os sucessivos planos de estabilização mal-sucedidos; já nos anos 1990, com a abertura comercial e a implementação do Plano Real, predominou a influência dos choques aleatórios, decorrentes de inovações tecnológicas, organizacionais e institucionais - incluindo processos de terceirização , na mudança setorial do emprego; e na recente década, após a reestruturação produtiva ocorrida na economia, houve o retorno do padrão anterior.

O restante do artigo foi organizado da forma que segue. No item 2, são discutidos a participação dos setores líderes nos ciclos econômicos e os deslocamentos da mão-de-obra entre os setores; no item 3 , é feita uma breve discussão sobre os impactos das mudanças na economia brasileira, nas últimas décadas, nos setores industriais; no item 4, está descrita a metodologia empregada; no item 5, fez-se uma análise de correlação entre dispersão do emprego setorial e vagas de trabalho normalizado, para obter uma distinção entre os choques provenientes de demanda e os aleatórios; no item 6, fez-se um estudo complementar, com o objetivo de identificar uma possível alteração do tipo de choque predominante após a desvalorização cambial de 1999; por último, no item 7, constam as principais conclusões do trabalho. 
Rodrigo Silva Barreto, Silvia Harumi Toyoshima, Guilherme Marciano Timm \& Tárik L. F. Pereira Navarro

\section{Referencial teórico}

\subsection{Ciclos econômicos e deslocamentos setoriais}

As diversas explicações sobre as origens e os comportamentos dos ciclos econômicos estão em conformidade com as diferentes vertentes teóricas relacionadas com desenvolvimento e crescimento econômico. Dentre elas, algumas relacionam os ciclos com mudanças tecnológicas, que, por sua vez, teriam impactos setoriais, gerando, em cada período, segmentos produtivos líderes. Rostow (1961), por exemplo, embora não se possa dizer que sua teoria comportasse estudos sobre ciclos econômicos, foi um dos autores que relacionaram cada etapa do capitalismo à presença de setores líderes. Cada uma das cinco etapas do desenvolvimento identificadas pelo autor comportava um estado de técnicas diferentes que estavam associadas a um conjunto de atividades produtivas principais.

Uma teoria dos ciclos relacionada com inovações tecnológicas, contudo, surgiu, explicitamente, com Joseph Schumpeter, em 1911, com a publicação da Teoria do Desenvolvimento Econômico. De acordo com Schumpeter (1961), o desenvolvimento não ocorre de forma uniforme no tempo, mas é alternado por períodos de prosperidade e depressão. Isto porque os principais fatores geradores de desenvolvimento, que são as inovações, não surgem de forma linear no tempo, mas em determinados períodos. A esse processo denomina de "destruição criativa", que ocorre quando novas empresas deslocam as antigas, criando não só novos produtos e processos, mas também novas indústrias. Dentre seus seguidores, Freeman et al. (1982) destacaram que as inovações não são distribuídas de modo aleatório na economia, mas tendem a concentrarse em certos setores-chave, de forma que os setores tornam-se muito desarmônicos e desiguais, naturalmente. Nessa mesma vertente teórica, Dosi (1988) argumentou que novos paradigmas tecnológicos alteram a estrutura produtiva das economias. Essas novas tecnologias, ao apresentar características de maiores cumulatividade de conhecimento, oportunidade de investimento e apropriabilidade de lucros extraordinários, geram 
assimetrias em todos os níveis - entre empresas, entre segmentos produtivos e até entre países.

Em suma, esse processo de destruição criativa, ao alterar a estrutura produtiva, altera também o mundo do trabalho, ao exigir novas habilidades e modificar a demanda de trabalho, incluindo modificações setoriais dessa demanda. Com a automação, por exemplo, exige-se maior conteúdo intelectual dos trabalhadores (como conhecimentos abstratos e domínio teórico), e os hiatos temporais existentes entre destruição e criação de empregos geram problemas sociais graves, o que torna o processo de introdução de inovações turbulento e doloroso, do ponto de vista social (Pastore, 1998).

Empiricamente, é difícil distinguir o desemprego associado a choques aleatórios, que inclui as inovações, da associado a choques de demanda. Brainard e Cutler (1993) exemplificaram, explicitamente, essa questão. Considere a ocorrência de um choque agregado adverso que, temporariamente, diminui os rendimentos de todos os setores. Desde que todos eles respondam, similarmente, a esse fato e não há mudança na distribuição de equilíbrio do capital, a dispersão dos rendimentos setoriais do capital não deverá aumentar, significativamente, durante o choque agregado. Agora, numa economia multissetorial, uma mudança na tecnologia ou nos gostos dos consumidores provocará elevação da dispersão setorial dos rendimentos do capital. O estoque de capital será reduzido em diversas indústrias, causando aumento no desemprego e diminuição das vagas de trabalho nesses setores. Inversamente, os investimentos elevarão nas indústrias afetadas positivamente. Com o tempo, a dispersão dos rendimentos do capital, entre os setores, estreitará progressivamente, em razão de o capital e de os trabalhadores moveremse para os setores mais produtivos.

As primeiras análises baseadas na hipótese de que deslocamentos intersetoriais dos trabalhadores em uma economia podem afetar a taxa de desemprego foram feitas a partir de meados da década de 70, com o trabalho de Lucas e Prescott (1974). Como demanda tempo para que o 
Rodrigo Silva Barreto, Silvia Harumi Toyoshima, Guilherme Marciano Timm \&

Tárik L. F. Pereira Navarro

trabalhador se desloque de um mercado para outro, os autores concluíram que há uma taxa de desemprego "natural", "friccional" ou de "equilíbrio". Lillien (1982) argumentou que os trabalhadores que se deslocam de um setor para outro precisam de certo tempo para se adaptarem à nova atividade. A partir de resultados empíricos da hipótese de deslocamentos setoriais, o autor observou que a taxa natural de desemprego sofre variações ao longo do tempo. Abraham e Katz (1986) apresentaram algumas críticas ao trabalho de Lillien (1982), ao argumentarem que em uma economia com dois setores, em que uma apresenta tendência de crescimento maior que o outro, mas menor sensibilidade aos ciclos, aumentos na demanda agregada teriam o efeito de diminuir o índice de dispersão, e reduções na demanda agregada fariam com que o índice de dispersão aumentasse. A queda na demanda agregada provocaria então aumento tanto no desemprego quanto no índice de dispersão. Com isso, a correlação positiva entre o índice de dispersão e a taxa de desemprego seria provocada, nesse caso, pela endogeneidade do índice em relação a movimentos da demanda agregada (Reis e Gonzaga, 2000), e não por modificação setorial pura na demanda, como pressuposto no trabalho de Lillien (1982).

Abraham e Katz (1986) elaboraram um modelo para separar choques setoriais puros de choques de demanda (Figura 1). No modelo, supõe-se que, quando ocorresse uma expansão da demanda agregada, dever-seiam esperar redução no nível de desemprego e elevação no número de vagas de trabalho disponíveis, enquanto redução na demanda agregada diminuiria o número de vagas disponíveis e aumentaria o nível de desemprego. Isto implica que, dadas as características estruturais da economia, pode-se estimar uma curva UV negativamente inclinada (Curva de Beveridge), que relaciona a variação do desemprego com a variação do número de vagas de trabalho.

A variação no desemprego está positivamente correlacionada com a dispersão setorial do emprego; e a hipótese de puros movimentos da demanda agregada implica que as distribuições da dispersão setorial do emprego (S) e das vagas de trabalho $(\mathrm{N})$ apresentariam direções opostas 
ao longo dos seus movimentos. Isso ocorre porque, por exemplo, quando há redução na demanda agregada, a oferta de trabalho ou o número de vagas $(\mathrm{N})$ diminui; mas os segmentos demitem de forma diferenciada, aumentando a dispersão setorial (S). Contrariamente, quando há puros movimentos setoriais, tanto o número de vagas $(\mathrm{N})$ como a dispersão setorial (S) aumentam.
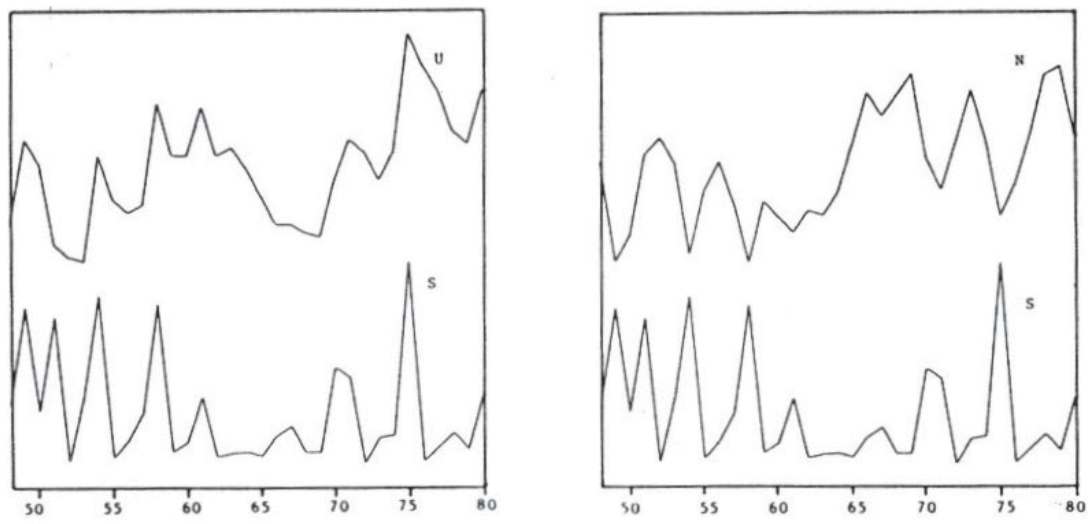

Figura 1 - À esquerda, tem-se a relação entre o desemprego (U) e a dispersão do emprego $(\mathrm{S})$. À direita, é mostrada a relação inversa entre a variação das vagas de trabalho $(\mathrm{N})$ e a dispersão do emprego (S). Dados americanos entre 1948 e 1980 (ABRAHAM E KATZ, 1986).

Além das mudanças na demanda setorial do emprego e dos puros movimentos setoriais, há outros elementos teóricos que contribuem para o entendimento da dispersão setorial do emprego, os quais serão brevemente discutidos, uma vez que não fazem parte da preocupação central do presente artigo.

Uma primeira questão diz respeito aos movimentos sindicais. Gittleman e Wolff (1993) comprovaram, a partir de um estudo empírico em diversos países, dentre outras conclusões, que a sindicalização tem importância para explicar as diferenças salariais entre as indústrias, o que tornaria alguns empregos mais atrativos que outros. No Brasil, Cardoso (2001) e 
Rodrigo Silva Barreto, Silvia Harumi Toyoshima, Guilherme Marciano Timm \& Tárik L. F. Pereira Navarro

Costa (2003) estão entre autores que discutiram as mudanças na economia brasileira durante a década de 90 , particularmente com o Plano Real, e as alterações nos movimentos sindicais. Ambos enfatizaram que o desemprego, decorrente do processo de reestruturação produtiva, foi um dos maiores responsáveis pelo enfraquecimento dos sindicatos, durante a década de 90. Cardoso (2001), ao fazer uma análise setorial de tal enfraquecimento, mostrou que a maioria dos segmentos perdeu em número de filiados (como o de extrativa mineral, de serviços de utilidade pública e o metalúrgico) e que outros aumentaram a filiação (ensino, material de transporte e borracha e fumo, principalmente). Esse autor verificou, ainda, o fortalecimento de sindicatos de categorias do setor terciário, indicando que o crescimento da participação deste no PIB refletiria no aumento da sindicalização. Assim, embora todos os segmentos produtivos tenham, num primeiro momento da reestruturação produtiva, reduzido o número de empregos, é de esperar que a resistência maior a essa redução tenha ocorrido naqueles em que o movimento sindical enfraqueceu menos.

A outra questão se refere às diferenças salariais entre setores, o que implica busca diferenciada de emprego por parte dos trabalhadores, de acordo com a remuneração paga pelos setores. A discussão básica, nesse ponto, é sobre a adequação da hipótese de que haveria correspondência entre características iguais dos trabalhadores e salários iguais. A não observância desse fenômeno levou à produção de inúmeros trabalhos que procuravam identificar os fatores que explicam tais diferenças como os relacionados com setores, regiões, gênero, raça, dentre outros (Dickens e Katz, 1987; e Krueger e Summers, 1988). No Brasil, Arbache e Negri (2002) verificaram que não só os atributos dos trabalhadores explicam o diferencial dos salários, mas também os das firmas, como tamanho das plantas, nacionalidade do capital e acesso ao mercado internacional, apesar de parte do diferencial não poder ser explicada pela pesquisa, o que sugere que as características industriais sejam fundamentais para tal explicação. Em outro artigo, Arbache e Negri (2004) encontraram evidências de que valor adicionado, margem de lucro e tecnologia industriais afetam o diferencial de salários. Lima e Abdal (2007) 
verificaram que existem diferenças setoriais no pagamento de salários para trabalhadores de nível superior, sendo que os mais bem remunerados estão empregados nas indústrias modernas e os que recebem menores salários se encontram no governo e nos serviços pessoais.

Uma terceira questão relaciona a estrutura de qualificação e habilidade com o emprego setorial. O artigo de Becker (1962) é considerado seminal para a discussão sobre investimentos em capital humano, salários e emprego. Esse autor verificou que o desemprego maior de pessoas menos qualificadas deve-se a menores investimentos feitos pelas empresas nesse perfil de trabalhador. Lima e Abdal (2007) mostraram, tomando o caso Brasil, que há diferenças setoriais no emprego de pessoas mais qualificadas. O governo e o setor de serviços pessoais são os que mais empregam pessoas com nível superior de educação, contudo, são os que pagam os menores salários.

Em suma, há diversos fatores, além da demanda e das inovações, que explicam as variações setoriais do emprego.

\section{Metodologia}

Para identificar os tipos de choques setoriais que incidiram entre 1986 e 2006, foi feita uma análise da correlação entre os índices de dispersão do emprego setorial (S) e o índice de vagas de trabalho normalizado (N), como sugerido por Abraham e Katz (1986). O índice N mede a variação das vagas de emprego, de maneira normalizada. Para normalizar este índice, dividem-se as vagas de trabalho disponíveis pela quantidade total de pessoas empregadas.

O índice de dispersão do emprego tenta captar a incidência dos choques setoriais ao longo do tempo, utilizando a diferença do logaritmo do emprego em setores da economia, definido por 
$S=\left[\sum_{i=1}^{j} \frac{x_{i t}}{X_{t}}\left(\Delta \log x_{i t}-\Delta \log X_{t}\right)^{2}\right]^{\frac{1}{2}}$,

em que $\mathrm{x}_{\mathrm{it}}$ é o emprego no setor $\mathrm{i}$, no tempo $\mathrm{t} ; \mathrm{X}_{\mathrm{t}}$, emprego agregado, no período $\mathrm{t}$; e j, número total de setores.

$\mathrm{O}$ índice $\mathrm{N}$ é definido por

$$
N=\frac{v}{p}
$$

em que v corresponde ao número de ofertas de empregos (demanda por trabalho); e p, número total de empregados.

A análise de correlação estuda o relacionamento entre variáveis, buscando medir uma possível covariabilidade entre elas, sem a preocupação de causa e efeito, podendo ser positiva, negativa ou nula (Gujarati, 2000). O cálculo do coeficiente de correlação, cuja variação está entre 0 e 1 , é dado por

$$
\operatorname{Correl}(S, N)=\frac{\operatorname{Cov}(S, N)}{\operatorname{Var}(S) \times \operatorname{Var}(N)},
$$

em que Correl $(S, N)$ é o coeficiente de correlação entre as variáveis $S$ e $N$; $\operatorname{Cov}(S, N)$ é a variância entre as variáveis $S$ e $N$; Var $(S)$ é a variância de $\mathrm{S}$; e $\operatorname{Var}(\mathrm{N})$, variância de $\mathrm{N}$.

Em seguida, foi feito o teste de significância unicaudal, uma vez que o sinal da correlação é fundamental para validar a hipótese da pesquisa.

Foram testados dois casos para períodos diferentes: $\left.1^{\circ}\right) \mathrm{H}=\mathrm{r} \geq 0$ contra $\mathrm{H}_{1}=\mathrm{r}<0$; e $\left.2^{\circ}\right) \mathrm{H}_{0}=\mathrm{r} \leq 0$ contra $\mathrm{H}_{1}=\mathrm{r}>0$. 
$\mathrm{O} 1^{\mathrm{o}}$ caso foi testado para períodos em que a dispersão setorial se deve, predominantemente, a movimentos na demanda agregada, no qual o sinal da correlação deve ser negativo, enquanto o $2^{\circ}$ caso, para períodos em que a dispersão setorial se deve a puros movimentos setoriais e o sinal da correlação deve ser positivo. Aqui, a suposição é de que a economia estaria sujeita a choques aleatórios, que, no período analisado, correspondem a choques de inovação.

Os dados, que consistem de séries temporais, foram submetidos a testes para verificação de estacionariedade, proposto por Dickey-Fuller, e a testes para verificação de cointegração entre as séries (Enders, 1995).

Ao fazer uma análise individual das curvas $\mathrm{S}$ e $\mathrm{N}$, utilizando um correlograma, observou-se que ambas são não estacionárias, por apresentarem declinação lenta dos coeficientes de autocorrelação ${ }^{7}$. Com o intuito de transformar as séries em estacionárias, trabalhou-se com a diferença. Segundo Vasconcellos e Alves (2000), uma série que precisa de d diferenças para tornar-se estacionária é denominada "não estacionária homogênea". Para saber o valor de d, ou seja, a ordem de integração de cada série, foi realizado o teste da Raiz Unitária.

Os dados sobre emprego e vagas de trabalho, no Brasil, foram extraídos do Ministério do Trabalho (Relação Anual de Informações Sociais - RAIS - e Sistema Nacional de Emprego - SINE), e os dados da RAIS e do SINE foram adquiridos diretamente do Ministério do Trabalho e Emprego (MTE).

Como os dados do SINE englobam apenas o emprego formal urbano, excetuando-se as vagas disponíveis do setor público - que são oferecidas via concursos - optou-se por trabalhar com os dados da RAIS para o cálculo do índice S. A identificação empírica dos choques setoriais predominantes será dada pelo estudo comparativo da correlação entre ambas as curvas, segundo metodologia de Abraham e Katz (1986).

\footnotetext{
A análise do correlograma é um dos instrumentos para identificar uma série estacionária. A presença de declinações lentas das barras que representam os coeficientes de autocorrelação indica a não estacionariedade da série. Em contrapartida, declinações rápidas dessas barras indicam que a série é estacionária. Devido à subjetividade desta avaliação, o correlograma por si só não é indicado para determinação da ordem das séries. Ver, para maiores detalhes, Vasconcellos e Alves (2000).
} 
Rodrigo Silva Barreto, Silvia Harumi Toyoshima, Guilherme Marciano Timm \& Tárik L. F. Pereira Navarro

\section{Resultados e discussão}

4.1. Distinção empírica entre os choques de demanda e os aleatórios

O cálculo e a análise do índice de dispersão setorial (S) e do índice normalizado de vagas de trabalho $(\mathrm{N})$ permitem identificar, empiricamente, os choques de demanda agregada e os choques aleatórios, sendo que este último supõe-se derivar, principalmente, de alterações no padrão produtivo e tecnológico, conforme argumentação no item 3.

De acordo com o teste de Raiz Unitária para as curvas $\mathrm{N}$ e S, utilizando a metodologia de verificação de integração Aumentado Dickey-Fuller (ADF), a 5\% sem intercepto e tendência, a curva $S$ é integrada de ordem 1. Pelo mesmo teste, a $5 \%$ sem intercepto e tendência, a curva $\mathrm{N}$ é integrada de ordem 2 . Neste caso, trabalhou-se com a curva $\mathrm{S}$, na primeira diferença, e com a curva $\mathrm{N}$, na segunda. Ao trabalhar na segunda diferença, perderam-se dois graus de liberdade, e o período a ser analisado passou a ser de 1988 a 2006, em vez de 1986 a 2006, como havia sido definido anteriormente. A Figura 2 mostra a relação entre as curvas S e $\mathrm{N}$ para o caso brasileiro, após ambas serem estacionarizadas. 


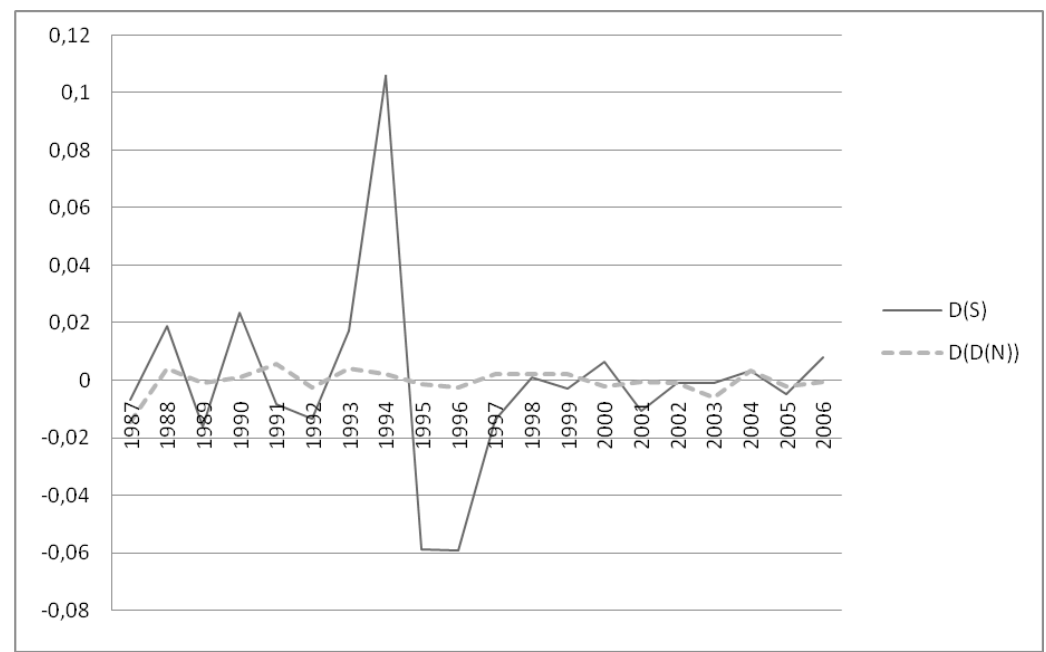

Figura 2 Relação estacionária das curvas S e N.

Fonte: Elaboração própria, a partir de dados da RAIS (MTE).

Conforme mencionado no referencial teórico, a hipótese de Abraham e Katz (1986) pressupõe que a indicação de predomínio de movimentos de demanda agregada se dê na presença de correlação negativa entre as curvas $\mathrm{S}$ e $\mathrm{N}$. Isso ocorre quando, por exemplo, é reduzida a oferta de trabalho - vagas $(\mathrm{N})$ diminuem -, por motivo de recessão (queda na demanda agregada). Como os segmentos demitem trabalhadores de forma diferenciada, a dispersão setorial do emprego aumenta; logo, $\mathrm{N}$ diminui e $S$ aumenta.

De modo contrário, detecta-se predomínio de puros movimentos setoriais quando a correlação entre ambas for positiva. Um tipo desses movimentos é o caso de inovação tecnológica, pois esta atinge, de forma diferenciada, os setores. Por exemplo, suponha que a indústria automobilística seja mais passível de automação e demita grande número de trabalhadores. Embora haja vagas no setor de vestuário, os trabalhadores demitidos não estarão qualificados para ocuparem essas vagas. Assim, poderá haver vagas crescentes, simultaneamente, com elevações na dispersão do emprego setorial. Logo, $\mathrm{N}$ e S aumentarão. 
Rodrigo Silva Barreto, Silvia Harumi Toyoshima, Guilherme Marciano Timm \&

Tárik L. F. Pereira Navarro

Ao analisar o comportamento das curvas S e N, na Figura 1, observa-se presença de um marcante outlyer na curva S, em 1994, o que indica forte dispersão no emprego setorial formal urbano neste ano. Esse fato pode ser reflexo de uma mudança na estrutura da demanda, com o plano de estabilização. A partir desse ano, acentuaram-se as modificações na estrutura produtiva brasileira, que tiveram reflexos no emprego setorial do país.

É possível ainda verificar, na figura, que no período 1986-93 há movimentos contrários entre as curvas S e N, principalmente após 1988, o que indica que a dispersão setorial do emprego ocorreu mais devido às alterações na demanda agregada. Após 1994, S e N apresentam movimentos mais semelhantes, principalmente entre 1997 e 2001.

Os testes de correlação entre as duas séries comprovaram o que se pode observar na Tabela 1, ou seja, no período 1986-93, a correlação foi negativa $(-0,718)$, o que indica predomínio de movimentos setoriais causados, principalmente, por variações na demanda agregada. $\mathrm{O}$ teste estatístico foi significativo a $10 \%$. Esse período correspondeu a dois planos fracassados de estabilização (Plano Cruzado e Plano Collor), o que dificultou qualquer mudança estrutural da economia, uma vez que o principal problema era a iminência da hiperinflação. Apesar de a abertura comercial ter ocorrido em 1990, o que exigiu um aumento na competitividade da produção brasileira, nos primeiros anos da década não foram observadas grandes mudanças na estrutura produtiva, mas foram anos de recessão devido ao impacto do Plano Collor. Portanto, grande parte da variação do emprego deveu-se a variações na demanda, e não a inovações tecnológicas e organizacionais. 
Tabela 1 - Teste de correlação entre Índice de Dispersão do Emprego (S) e Vagas (N), 1988-2006

\begin{tabular}{lcc}
\hline Período & Correlação & Valor da Estatística (t) \\
\hline $1988-1993$ & -0.718 & $-2.06444^{*}$ \\
$1994-2003$ & 0.508 & $1.669781^{*}$ \\
$2004-2006$ & -0.715 & 1.02405 \\
\hline
\end{tabular}

Fonte: Elaboração dos autores.

* Significativo a $10 \%$.

No período 1994-2003, a correlação foi positiva $(0,508)$, o que mostra que as mudanças setoriais do emprego ocorreram, principalmente, devido a choques aleatórios. O teste, da mesma forma, foi significativo a $10 \%$, o que corrobora a hipótese inicial da pesquisa, para esse período. $\mathrm{O}$ ano inicial dessa série, 1994, correspondeu à implantação do Plano Real. Uma das políticas utilizadas para que o plano fosse bem sucedido foi a liberação das importações, cujo objetivo era manter os preços estáveis, seja pela oferta de produtos, seja pela concorrência externa imposta aos produtores internos. Isso levou a uma onda de inovação que reestruturou todo o setor produtivo, principalmente o secundário, contribuindo para a queda dos custos e, consequentemente, dos preços, dentre outras mudanças. Esse resultado, também, está de acordo com os pressupostos do trabalho.

Por fim, no período 2004-2006, observa-se que o sinal da correlação entre $\mathrm{S}$ e $\mathrm{N}$ volta a ser negativo, o que demonstra que grande parte da dispersão setorial foi devida a variações na demanda agregada. Nesse caso, o teste estatístico não foi significativo a $10 \%$, o que pode ser explicado pelo período curto de anos analisados. Contudo, o sinal foi o esperado (negativo), o que sugere que as grandes alterações na estrutura produtiva foram efetuadas, no período anterior, a partir do novo paradigma tecnológico e produtivo, e a economia tornou-se mais estabilizada, no que se refere às participações relativas dos setores no produto. 
Rodrigo Silva Barreto, Silvia Harumi Toyoshima, Guilherme Marciano Timm \&

Tárik L. F. Pereira Navarro

Como mencionado anteriormente, vários autores apontam busca de maior competitividade pela indústria interna, intensificada a partir de 1994. Nesse contexto, percebe-se uma mudança na estrutura do emprego brasileiro a partir deste ano, sendo que, com o novo paradigma produtivo e tecnológico, houve modificação no peso dos segmentos produtivos.

A conclusão desta parte do trabalho é que a abertura comercial por si só, ocorrida em 1989, não alterou profundamente a estrutura produtiva do país. Esse processo foi acentuado a partir da implementação do Plano Real, o que explica o comportamento do emprego setorial, no período de 1994-2003. Antes de 1994, mais precisamente no período 1986-1993, as alterações do emprego setorial decorreram, predominantemente, de mudanças na demanda agregada.

4.2. Algumas considerações sobre o comportamento recente da dispersão do emprego setorial brasileiro

Como demonstrado em seções anteriores, a implantação do Plano Real, em 1994, alterou as causas da dispersão do emprego setorial brasileiro. Tais mudanças ocorreram, principalmente, devido à busca de competitividade pelos agentes privados, incluindo o processo de privatização, em razão da abertura comercial com a valorização do câmbio até 1998, o que permitia a entrada de produtos estrangeiros a preços mais baixos do que os produzidos nacionalmente.

Com a maxidesvalorização cambial em 1999, que tornou os preços dos produtos estrangeiros relativamente mais altos, a dispersão do emprego setorial poderia voltar a ser predominantemente explicada por movimentos de demanda. Isso porque a compra externa de bens de capital e bens intermediários, necessários ao processo de reestruturação produtiva, poderia ser dificultada.

A Figura 3 mostra o resultado da correlação entre as curvas S e N, no período de 1999 a 2003. Ao analisar a correlação entre a dispersão do 
emprego setorial e o índice de vagas de trabalho, com base no pressuposto de Abraham e Katz (1986), verifica-se que a desvalorização cambial, deflagrada a partir de 13 de janeiro de 1999, não alterou as causas predominantes da dispersão do emprego setorial brasileiro. Logo, choques de produtividade continuaram predominando na dispersão do emprego setorial brasileiro. Nesse período, a correlação entre o índice de vagas de trabalho e a dispersão do emprego setorial foi bem maior, passando de $34 \%$ para quase $70 \%$.

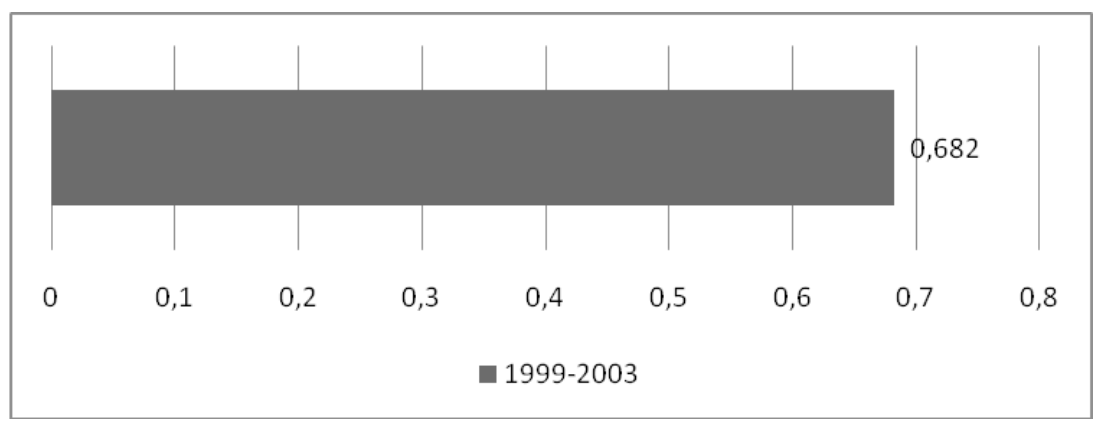

Figura 3 - Correlação entre as curvas S e N, de 1999 a 2001. Fonte: Elaboração própria, a partir de dados do MTE.

A desvalorização do câmbio, associada à baixa demanda interna e à precariedade da estrutura interna - como problemas institucionais, de infraestrutura, dentre outros - estimulou a continuidade na busca de maior competitividade, para maior inserção dos produtos nacionais no mercado externo.

Conclui-se, nesta parte, que a desvalorização cambial de 1999 estimulou a busca de maior competitividade do produto nacional, ao facilitar o acesso destes no mercado internacional. Com base em Lamounier (1999), Lahóz (2000) e Revista Exame (1999), citados anteriormente, pode-se inferir que as indústrias brasileiras se preocuparem não apenas com a entrada de produtos estrangeiros no mercado interno, mas também com a ampliação de suas vendas dirigidas ao comércio externo. Tal fato deu 
Rodrigo Silva Barreto, Silvia Harumi Toyoshima, Guilherme Marciano Timm \& Tárik L. F. Pereira Navarro

prosseguimento aos processos de reestruturação, gerando choques aleatórios que predominaram sobre a dispersão do emprego setorial brasileiro nesse período.

\section{Conclusões}

No presente estudo, no tocante à diferenciação dos tipos de choques sobre o emprego setorial para o mercado formal, foi constatado que, anteriormente ao Plano Real, os choques predominantes eram referentes a movimentos de demanda agregada, enquanto os predominantes foram decorrentes de movimentos setoriais puros, atribuídos à reestruturação tecnológica, organizacional e produtiva, conforme argumentação de diversos autores. A partir de 2004, volta-se ao padrão anterior.

Ao fazer uma comparação com a abertura comercial, percebeu-se que esta não alterou imediatamente, de modo significativo, a estrutura produtiva brasileira no mercado formal. No entanto, de acordo com o comportamento do emprego setorial, a partir a implementação do Plano Real, constatou-se que este acentuou o processo de reestruturação, em busca de maior competitividade. Isso é explicado pela política de estabilização, que liberou a entrada de produtos importados a partir desse período, a fim de manter os preços internos baixos, o que levou a um intenso processo de melhoria nos produtos e redução dos custos.

Observou-se que o processo de reestruturação prosseguiu após a grande desvalorização cambial, de 1999. Houve maior busca de competitividade pelas firmas brasileiras para inserção no mercado externo, o que fez com que os choques aleatórios continuassem predominando, como causa principal, na dispersão do emprego setorial brasileiro.

Finalmente, a partir de 2004, mais de dez anos após a abertura comercial e a implantação do Plano Real, o processo de reestruturação econômica brasileiro teve seus efeitos transitórios reduzidos. A partir desse período, observou-se que as variações de emprego entre os setores voltaram a ocorrer com mais frequência, devido a movimentos na demanda agregada. 


\section{Referências}

ABRAHAM, Katharine G., KATZ, Lawrence F. Cyclical unemployment: sectoral shifts or aggregate disturbances? Journal of Political Economy, v. 94, n. 3, p. 507-522, 1986.

ARBACHE, Jorge S., NEGRI, João A. Filiação industrial e diferencial de salários no Brasil. Revista Brasileira de Economia, v. 58, n. 2, p. 159-184, 2004.

ARBACHE, Jorge S., NEGRI, João A. Diferenciais de salários interindustriais no Brasil: evidências e implicações. Texto para discussão. Brasília: IPEA, 2002. 27 p.

BAUMANN, Renato Uma visão econômica da globalização. In: BAUMANN, Renato (Org.) O Brasil e a economia global. Rio de Janeiro: Campus, 1996. p. 33-51.

BECKER, Gary S. Investment in human capital: a theoretical analysis. Journal of Political Economy, v. 70, n. 5, p. 9-49, 1962.

BRAINARD, Lael S., CUTLER, David M. Sectoral shifts and cyclical unemployment reconsidered. Quarterly Journal of Economics. Massachussetts/IT, v.108, 1993.

CARDOSO, Adalberto M. Problemas de representação do sindicalismo brasileiro: o que aconteceu com a filiação sindical? En publicacion: Los sindicatos frente a los processos de transición política. In: TOLEDO, Enrique G. Clacso. 2001. Acesso ao texto completo: http:// bibliotecavirtual.clacso.org.ar/ar/libros/garza3/cardoso.pdf.

COSTA, Márcia S. C. Reestruturação produtiva, sindicatos e a flexibilização das relações de trabalho no Brasil. RAE-eletrônica, v.2, n. 2, p. 1-16, 2003. 
Rodrigo Silva Barreto, Silvia Harumi Toyoshima, Guilherme Marciano Timm \& Tárik L. F. Pereira Navarro

DICKENS, William T., KATZ, Lawrence. Inter-industry wages differences and theories of wages determination. NBER Working Paperr, n. 2271, 1987.

DOSI, Giovanni Institutions and markets in a dynamic world. The Manchester school, v. 56, n. 2, p. 119-146, 1988.

ENDERS, Walter Applied econometric time series. New York: John Wiley \& Sons, 1995. p. 433.

FREEMAN, Christopher, CLARK, J., SOETE, Luc Unemployment and Technical Innovation. London: Frances Pinter, 1982. 214p.

GITTLEMAN, Maury, WOLFF, Edward N. International comparisons of inter-industry wage differentials. Review of Income and Wealth, v. 39, n. 3, p. 295-312, 1993.

GUJARATI, Damodar N. Econometria básica. São Paulo: MAKRON Books, 2000. 846p.

KRUEGER, Alan B., SUMMERS, Lawrence H. I. Reflections on the inter-industry wage structure. NBER Working Paper Series, n 1968, 1986.

LILIEN, David M. Sectoral shifts and cyclical unemployment. Journal of Political Economy. Chicago/University, v. 90, n. 4, p. 777-793, 1982.

LIMA, Márcia, ABDAL, Alexandreado. Educação e trabalho: a inserção dos ocupados de nível superior no mercado formal. Sociologias, v. 9, n. 17, p. 216-238, 2007.

LUCAS, Robert E., PRESCOTT, Edward G. Equilibrium search and employment. Journal of Economic Theory, v. 7, p. 188-209, 1974.

MATTOSO, Jorge A desordem do trabalho. São Paulo: Página Aberta, 1995.210p. 
MINISTÉRIO DO TRABALHO E EMPREGO (MTE). Bases Estatísticas. Relação Anual de Informações Sociais (RAIS). Brasília, 1985-2001.

MINISTÉRIO DO TRABALHO E EMPREGO (MTE). Intermediação de mão-de-obra. Sistema Nacional de Emprego. Brasília, 1985-2001.

PASTORE, José Tecnologia e Emprego. Parcerias Estratégicas, n. 5, p. 36-93, 1998.

REIS, Maurício, GONZAGA, Gustavo Desemprego e deslocamentos setoriais da demanda por trabalho no Brasil. In: FONTES, Rosa M. O., ARBEX, Marcelo A. (Orgs.). Desemprego e mercado trabalho: ensaios teóricos e empíricos. Viçosa: UFV, p. 215-251, 2000.

REVISTA EXAME Agora, é aqui dentro. São Paulo: Abril, ed. 680, 27 Jan., 1999.

ROSTOW, Walt W. Etapas do desenvolvimento econômico - um manifesto não comunista. Rio de Janeiro: Zahar, 1961.

SCHUMPETER, Joseph A. Capitalismo, socialismo e democracia. Rio de Janeiro: Fundo da Cultura, 1961. 512p.

SCHUMPETER, Joseph A. Teoria do desenvolvimento econômico. São Paulo: Abril Cultural, 1982. 168 p.

VASCONCELlOS, Marco A. S., ALVES, Denisard Manual de Econometria. São Paulo: Atlas, 2000. 308p. 
Abstract: The purpose of this article was to evaluate the impact of recent changes in Brazilian economy on to sectoral employment structure, in the period 1988-2006, through the identification of the main explanations of sectoral dispersion of employment, with the largest exposure of the Brazilian economy to the international market and mainly after implementation of the Plano Real. The methodology consisted in the calculation of an index of sectoral dispersion of employment followed by a correlation test between sectoral dispersion index and normalized index of the number of available jobs. The results show that before the implementation of the Plano Real changes in sectoral demand were the main reason for modifications in sectoral changes of employment. On the other hand, pure sectoral changes, attributed to the technological, organizational and productive changes, were verified after the Plano Real, in 1994. Since 2004, the results indicate that economic changes' effects have reduced and the sectoral changes of employment happen again more owing to changes in sectoral demand.

Keywords: sectoral dispersion of employment, productive, technological and organizationl changes, demand changes. 
REVISTA DE ECONOMIA E AGRONEGÓCIO, VOL.8, $N^{o} 1$

\section{ANEXO 1}

Índice S - Índice de Dispersão Setorial e Índice N - Vagas de Trabalho (índice normalizado)

\begin{tabular}{|c|c|c|}
\hline Ano & $S$ & $\mathrm{~N}$ \\
\hline 1985 & & 0,034811167 \\
\hline 1986 & 0,029015822 & 0,039360086 \\
\hline 1987 & 0,022518997 & 0,029398013 \\
\hline 1988 & 0,041538917 & 0,023576998 \\
\hline 1989 & 0,025444808 & 0,016779689 \\
\hline 1990 & 0,048819045 & 0,010965075 \\
\hline 1991 & 0,040634959 & 0,010941518 \\
\hline 1992 & 0,027328678 & 0,008337732 \\
\hline 1993 & 0,04472934 & 0,009838581 \\
\hline 1994 & 0,150497399 & 0,013642486 \\
\hline 1995 & 0,092013355 & 0,016026193 \\
\hline 1996 & 0,032973918 & 0,016182961 \\
\hline 1997 & 0,019407266 & 0,01878317 \\
\hline 1998 & 0,020315951 & 0,023593494 \\
\hline 1999 & 0,017359186 & 0,030744876 \\
\hline 2000 & 0,023822619 & 0,036018627 \\
\hline 2001 & 0,013188627 & 0,040720916 \\
\hline 2002 & 0,012185269 & 0,044526108 \\
\hline 2003 & 0,011413281 & 0,042274171 \\
\hline 2004 & 0,014988975 & 0,043657619 \\
\hline 2005 & 0,010248324 & 0,042986024 \\
\hline 2006 & 0,01826794 & 0,041688255 \\
\hline
\end{tabular}

Fonte: MTE/SINE 